\title{
- Surveillance \& society The Work of Art in the Age of Artificial Article Intelligence: What Artists Can Teach Us About the Ethics of Data Practice
}

\section{Luke Stark}

Microsoft Research, Montreal, Canada

luke.stark@microsoft.com
Kate Crawford

New York University, USA

k8@,factorypreset.com

\begin{abstract}
Problematic use of data, patterns of bias emerging in AI systems, and the role of platforms like Facebook and Twitter during elections have thrown the issue of data ethics into sharp relief. Yet the focus of conversations about data ethics has centered on computer scientists, engineers, and designers, with far less attention paid to the digital practices of artists and others in the cultural sector. Artists have historically deployed new technologies in unexpected and often prescient ways, making them a community able to speak directly to the changing and nuanced ethical questions faced by those who use data and machine learning systems. We conducted interviews with thirty-three artists working with digital data, with a focus on how artists prefigure and commonly challenge data practices and ethical concerns of computer scientists, researchers, and the wider population. We found artists were frequently working to produce a sense of defamiliarization and critical distance from contemporary digital technologies in their audiences. The ethics of using large-scale data and AI systems for these artists were generally developed in ongoing conversations with other practitioners in their communities and in relation to a longer history of art practice.
\end{abstract}

\section{Introduction}

You walk into a gallery. Around you is a series of installations. One shows millions of appropriated Facebook profiles, which have been turned into a new dating site without the knowledge of the users. A portrait hangs on the wall, having been generated by a type of machine learning algorithm known as a generative adversarial network. Next to this, you see a dozen hanging faces resembling US military whistleblower Chelsea Manning, but each is a different interpretation of her DNA profile. A video installation shows BINA48, a "sentient robot," deep in a conversation about race and politics in America. As you walk away and regain cellular access, you suddenly receive an unprompted text message: "Welcome to Your NSA Partner Network."

This particular gallery show may be hypothetical, but all these works of art are real. These pieces are material examples of a broader conversation in the art world about corporate and state surveillance, artificial intelligence (AI), and the ethics of large-scale data use. The proliferation of hacked data, the patterns of bias emerging in AI systems, and the role of social media platforms like Facebook and Twitter during elections have all thrown the centrality of data ethics - the social and normative dimensions and ramifications of digital systems - to contemporary social life into sharp relief (Vallor 2018; Metcalf, Heller, and boyd 2016; boyd and Crawford 2012). In the past five years, artists have played a significant role in contending with these issues, as data systems touch more and more facets of everyday life. 
Yet the widening conversation about data ethics has centered chiefly on computer scientists, engineers, and designers (Moor 2001; Westin 2003; Lyon 2014). The lack of attention on artists and the cultural sector in this burgeoning literature is surprising given that artists have historically deployed new technologies in unexpected and often prescient ways (Shanken 2002; Rieland 2014) and have been interpreted as vanguards: of new ideas, techniques, and cultural practices (Francastel 2000). In this paper, we focus on the ethics of digital art practice as a necessary addition to recent scholarship on ethics and digital technologies (Crawford and Schultz 2013; Dignum 2018; Markham, Tiidenberg, and Herman 2018). Artists engaging with data analytic tools and computational techniques can share their opinions on the ethical importance, impact, and implications of their projects, often without being beholden to particular companies or platforms. This makes them a significant but often undervalued community able to speak directly to the changing and nuanced ethical questions faced by those who use data, machine learning (ML), and AI in their work.

The degree to which aesthetics, or the formal qualities of a work of art, are tied to human ethics is a live and longstanding debate among philosophers (Carroll 2000). Our exploration of the ways that artists are using data and algorithmic tools creatively provides a window into both new aesthetic domains and underexplored ways of thinking about ethical practice in societies already heavily mediated by computational technologies. Through speaking with contemporary artists, we heard a different set of dilemmas emerge at the intersection of aesthetics, ethics, and politics in the everyday use of data tools. In choosing to survey artists as leading data practitioners who are thinking explicitly about ethics, we discovered rich connections between ethics, data practice, and aesthetics. These discourses around art, data, and ethics can help inform wider debates about the ethical use of artificial intelligence and related technologies and the ways human values are inextricably tied up in the parameters of everyday practices.

\section{Art, Data, and Machine Interventions}

The multi-decade history of artworks engaging with digital and networked tools is too extensive to give anything more than a briefest possible treatment here; others have produced more comprehensive accounts of some of its historical antecedents (Marks 2010), developments in the field since advances in digital computing (Paul 2015; Higgins and Kahn 2012), and theories of its development in relation to other art forms (Bolter and Grusin 2000). These artistic genres go by many names - new media art, AI art, computational art, or internet art-suggesting often-overlapping definitions of style and materials and serving to delimit particular communities of practice (Grau 2004; Popper 2006).

In this paper, we focus on artists who are directly addressing social tensions around privacy, surveillance, identity, and power as mediated by data, AI, and ML in their artistic output. These are the same sociotechnical developments that have engaged surveillance studies and critical data studies for some time (Levin, Frohne, and Weibel 2002). Scholars in surveillance studies and related disciplines have examined the importance of artistic representations of digital surveillance and privacy intrusions across media forms. These genres have included architecture (Steiner and Veel 2011), film (Kammerer 2004; Muir 2015; Zimmer 2015), literature (Rosen and Santesso 2013), popular music (Marx 2009), and digital games (Whitson and Simon 2014). Others have focused more closely on surveillance and artistic practice (Finn 2012), including both photography (Feldman 2005; Barnard-Wills and Barnard-Wills 2012) and new media or digital art (Gonzalez 2009; Ahnert 2017). Surveillance art, a genre which both predates and includes examples from the contemporary era of social media and large-scale data analytics, holds within its tradition familiar ambiguities about power, audience, the status of artists, and their role in social life (Remes and Skelton 2010).

Yet artworks drawing on large-scale data analytics and artificial intelligence can also raise their own ethical concerns - artists can be just as drawn to the seduction of "seeing" into large swaths of the population through using large-scale data. Whistleblower Edward Snowden's disclosure in 2013 of the data collection practices of the United States National Security Agency (NSA) was one recent catalyst for a growing critical awareness of the ethical risks present in working with large-scale data surveillance, and by extension such practices have implicated a wide range of artistic endeavors as ethically and politically charged (Pollack 
2014). "There is a marked difference in how we view surveillance before and after Snowden came forward," notes artist and filmmaker Laura Poitras, and cultural interventions have played a significant role in this cultural shift — such as her Oscar-winning 2014 film, Citizenfour. Other events such as the data-collection scandal surrounding voter analytics firm Cambridge Analytica and its role in the election of Donald J. Trump as President of the United States have prompted further reflection. In response, artists have been able to draw on different modes of expression than the ones traditionally available to journalists or activists, and they can offer powerful insights into the broader social and political questions of contemporary data practices (Poitras and Crawford 2015).

Our study primarily focuses on art produced in the last ten years, with emphasis on how artists prefigure and challenge data practices and ethical concerns of computer scientists, researchers, and the wider population. The past decade encompasses renewed attention to ethical practices in computer science, the increased dominance of machine learning, the Snowden leaks, and the controversial 2016 US election where Facebook and Twitter data were manipulated in order to try to influence voters at scale. We collected qualitative, semi-structured interviews of thirty-three practicing artists and designers based in North America, the Middle East, and Europe doing data art. ${ }^{1}$ We asked artists to comment on their history of creative practice, the ways in which they engaged with digital data in their artwork, and how contemporary conversations around privacy and surveillance have shaped their practice. We also asked artists what ethical responsibilities they felt they had toward their audience, other artists, and data itself.

We performed content analysis on the texts of these interviews and supplemented this corpus with secondary research and observational visits to conferences and gatherings such as the international UX/visualization Eyeo conference in Minneapolis, Minnesota; the Seven on Seven conference hosted by art magazine Rhizome at the New Museum in New York City; and a range of exhibitions and artist meet-ups in the US and Europe. ${ }^{2}$ Thematically, the artists we interviewed for the project have all produced work reflecting on the status of individuals and communities in a networked, data-saturated world of analytics and persistent tracking. Across the interviews, we heard differences in how artists perceive these issues and were shown a variety of approaches in how to address ethical questions conceptually, aesthetically, and technically. But there were strong themes in common: in particular, concern about the political economy of data, unease about growing surveillance across the public and private sector, and an ambivalence about the artist's role in interpreting or intervening within this complex set of forces. ${ }^{3}$

The artists we spoke with for this study varied in notable ways, including in how they described themselves. Some were well established professionally, while others were early in their careers. Artists were often connected socially through a web of overlapping institutional, mediated, and personal affiliations. Online mailing and discussion lists, such as the Artsec and Empyre lists, were important zones for community engagement, helping artists bridge geographic distances between centers of creative practice. These online forums also provided a platform to share news about events, discuss technical practices, and develop new opportunities for collaboration. These artists also connected at more formal gatherings, such as the Eyeo and Hackers On Planet Earth (HOPE) conferences in the US, the Ars Electronica conference in Austria, and Re:publica and Chaos Computing Club meetings in Germany. At these events, artists demonstrated or prototyped work, fomented ideas for new projects, and connected with experts in fields such as interaction design and computer security and advocates from organizations such as Electronic Frontier Foundation

\footnotetext{
${ }^{1}$ We focused on artists using contemporary networked computational tools and platforms, data, and databases. The artists we spoke to were located predominantly in New York City, Chicago, Portland, and San Francisco, and in European cities such as Paris, London, Istanbul, and Berlin.

2 More information can be found at http://eyeofestival.com/ and http://rhizome.org/.

${ }^{3}$ Interviews varied from between twenty-five to ninety-five minutes in length, and all participants were given the opportunity to be interviewed on background, quoted anonymously, or quoted using their real name (the latter being the option the vast majority chose). All artists were interviewed under the auspices of Microsoft Research's internal research ethics protocols.
} 
(EFF) and the Electronic Privacy Information Center (EPIC). The artists we spoke to often had deep social and intellectual links to computer science researchers, academics, and journalists.

In other significant ways, however, the conferences and artist communities we observed were relatively homogenous, in terms of race, ethnicity, and socioeconomic status. Technology companies in Silicon Valley suffer from some well-recognized problems with both a general lack of ethnic and racial diversity and disparities of influence and reach for minority voices (New York Times Editorial Board 2014; Isaac 2015). We saw a similar issue with the more established artists working with data in the developed West, mirroring broader problems in the art world as a whole (Banks 2017).

As such, this project was not intended as comprehensive or representative of all artists in this space; the artists we interviewed were contacted through informal snowball sampling and represent a particular, relatively high profile cross section of practitioners. ${ }^{4}$ Persistent structural inequalities exist in both the art and digital media worlds (Levin 2017). Despite a broad awareness of this issue among the artists we interviewed, lack of diversity remains a strong pattern. Digital surveillance is a global phenomenon provoking responses from artists around the world - our sample of artists is primarily North American and European, and comparative responses by artists from other regions would be a welcome continuation of this scholarship. Some of the practitioners we interviewed were trained as visual artists, but many had backgrounds in other fields, including electrical engineering and computer science, musical composition or production, and interaction and user experience (UX) design. The artists we interviewed identified institutions such as New York University's Interactive Telecommunications Program (ITP) and New York's Eyebeam Art + Technology Center as important venues for considering the ethical implications of their practices, both as working artists and as teachers and mentors.

Art drawing on large-scale data and AI is primarily being made within both an increasingly professionalized technology sector and an increasingly professionalized art community. "If you're a programmer who became an artist, it's a lot cooler than being an artist who became a programmer," Ingrid Burrington, one of the artists we interviewed, noted [interview]. This split within practicing artists mirrored divisions in other interdisciplinary fields engaging with technical systems. It also reflects the high social and business value placed on "technical" or computational skill, in practice translating as facility with hardware, programming, and code.

\section{Defamiliarizing Data}

For many of the artists we interviewed, the question of ethics was at the crux of their practice with data and computational tools. The growing public awareness of threats to democratic governance and social cohesion stemming from data manipulation and surveillance was a starting point for many of our interviewees (Madden and Rainie 2015; Tufekci 2017). Artists noted how computational media and modes of data collection were increasingly integrated into people's routines and habits: the centrality, and difficulty, of thinking through the connections between digital aesthetics and ethics was urgent because of the intertwining of predictive analytics and behavioral targeting into the fabric of everyday life. As a result, "I'm always trying to blur this line between real life and an art project," observed LA-based artist and interaction designer Lauren McCarthy [interview]. McCarthy, an Assistant Professor at UCLA Design Media Arts, has developed artistic projects through the medium of the app itself, including the Crowdpilot smart phone app (McCarthy 2013), which will "stream your conversation to the web where the anonymous crowd - optionally supported by a team of your Facebook friends - will tune in, follow along, and assist you." McCarthy was explicit about her desire to defamiliarize digital technology through her work: "I kind of go in [to an art exhibit] with an idea like I'm going to see something weird, whereas if you're just confronted in your daily pattern it will reflect on what you're doing at that moment," she noted [interview]. This strategy of defamiliarization, which has a long history in nineteenth- and twentieth-century art

${ }^{4}$ Direct quotes from artists are included here where they illustrate broadly representative opinion for coded themes that resonate across all our interviews or where they disagree strongly with that opinion. 
(Shklovskij 1998; Gunn 1984), was a significant recurring theme among the artists we interviewed. Like guerilla interactive artists such as the Yes Men (Perini 2010), McCarthy's work seeks to closely capture the texture of digitally mediated life in ways that are both "replicatory and reiterative" of consumer technologies, while introducing moments of strangeness and alienation to prompt stronger audience reflection (Raley 2009: 12).

Many artists sought to provoke audiences by defamiliarizing the opaque and proprietary nature of software tools commonly covered by trade secret protections and functioning as "black boxes" (Pasquale 2015). "The market is pushing technology toward convenience," observed Paris-based artist Evan Roth, "and any time technology goes to convenience we lose freedoms within that technology" [interview]. Echoing longstanding work in science and technology studies (Latour 1983), artists like Roth noted that the design of digital technologies is increasingly remote and illegible to users. Roth's ongoing series of paintings, titled Multi-Touch, seeks to disrupt everyday interactions with networked devices like smart phones by translating the gestural language of swiping across a screen into abstract painting (Roth 2012; Stinson 2014), attempting to defamiliarize the quotidian practices of interaction between humans and machines.

Other artists described deploying defamiliarization to mobilize audience emotions as an explicitly ethical act. "Art has this ability to give someone an experience of something," observed Heather Dewey-Hagborg, a mixed-media artist and faculty member at the Art Institute of Chicago [interview]. Dewey-Hagborg is widely known for her 2013 project Stranger Visions - which created human masks from DNA obtained from found objects such as chewing gum and cigarette butts (Dewey-Hagborg 2013) - and her 2017 piece Probably Chelsea, presenting thirty different portraits based on the DNA of whistleblower and trans activist Chelsea Manning (Dewey-Hagborg 2017). The aim of both works was to make quotidian devices, data practices, and identities seem unfamiliar and uncanny.

Likewise, digital media artist Julian Oliver sought to engender "a productive paranoia... a healthy anxiety if you like" [interview]. Oliver and Danja Vasiliev created the 2014 Berlin Transmediale festival project Prism: The Beacon Frame (Oliver 2014) to send text messages purporting to be from the NSA to visitors' phones. By scrambling the familiar bounds of individual and collective consent, Oliver and other artists sought to draw attention, both intellectually and viscerally (Stark 2016), to the realities of how we perceive the privacy and connectivity of digital devices. Likewise, British artist and author James Bridle's projects seek to foreground and make explicit the ways networked data systems interact with the material world: his 2014 The Right to Flight involved launching a weather balloon over London equipped with free anonymous Wi-Fi routers and accessible mesh networks to highlight the dangers of the internet's corporate control (Bridle 2014a), while his 2017 piece Autonomous Trap 001 uses a simple chalk circle to confuse the visual sensors of a self-driving car (Mufson 2017).

The artists we interviewed sometimes deployed techniques of defamiliarization to make unfamiliar elements of computational technology seem normalized and domestic, as with Crowdpilot; in other cases, such as Oliver's Prism, artists presented everyday abstracted objects and practices as alien or discomforting. Sometimes the work focused on showing where systems fail, or how they can be turned against themselves, like Bridle's trapped autonomous car. Tactics of defamiliarization were matched with the desire to produce a strong emotional response. Many of the artists we interviewed claimed they wanted audiences to confront their relationship to technology when presented with their artwork: forcing a kind of friction and reflection was central to the ethical impact these artists sought rather than producing the "right" emotional effect. These artists sought to make audiences reflect on how artificial intelligence and data systems are embodied — not abstract — elements of everyday existence.

\section{The Ethics of Defamiliarization}

Some artists we interviewed admitted to being seduced by the technical capacities of large-scale data acquisition and analysis. "I was interested in how much people put out there on dating sites and I was interested in how appallingly easy it is to derive a serious lock on those people," composer, academic, and 
data artist Luke DuBois observed in relation to his 2011 project A More Perfect Union [interview]. DuBois' piece used data scraped from the dating website "OkCupid" to map the often idiosyncratic tastes and preferences of Americans" online dating profiles, visualizing the results in the idiom of "red" and "blue" states (DuBois 2011). For Dubois, a fascination with the dynamics of privacy and exposure was mixed with ambivalence about the ethics of using personal data without explicit consent.

This ambivalence, and the ethical questions it presented to artists like Dubois, raised the question of the extent an artist could and should open the black box of personal data in order to expose the structure of the box itself. "It's not a nice thing," observed DuBois, "to do a data portrait of someone against their will" [interview]. In DuBois's view, an artist's task was to remind individuals how the abstract quality of information should not be allowed to stand at face value - that such information can be used to create detailed, intimate insights into our lives.

DuBois's work foreshadows events like the extraction of Facebook data by Cambridge Analytica before the 2016 US election and the scraping of dating site data to produce a machine learning algorithm claiming to "detect" if someone was gay (Wang and Kosinski 2018). In both cases, users were unaware that their data were being used in ways to precisely target them and make predictions about their preferences - political or sexual or otherwise. The practice of doing data portraits without the consent of the subject has only become more significant as a business model in the past eight years, since DuBois began scraping social media platforms to produce critical works of art.

Some artists expressed ambivalence about the boundaries around the creative use of others' personal data. "The fact that you see so many people giving away their data and their information and not being worried about what that information could mean for a private company or for anyone from a criminal to a governmental agency is also new," suggested Italian conceptual artist Paolo Cirio, winner of the 2014 Prix Ars Electronica [interview]. Cirio's work included his 2013 project Street Ghosts, in which Cirio printed and pasted life-size printouts of individuals captured by Google Maps in the same location in which their photos were captured. The piece plays with the dynamic of privacy and publicity in a particularly frank way: Cirio did not seek permission of his subjects, although he noted he respected requests for a person to be removed from the project (Cirio 2013).

Media theorist Rita Raley has suggested the work of data artists like Cirio performs a type of "speculative practice," with their distinctiveness resting on being "not only generative but also intellectually responsive" to the economic realities of data use (Raley 2009: 115). By extension, artists using these data analytic systems also participate in an ethics of responsiveness, particularly those projects that engage explicitly in the ethics of digital systems and their use. To varying degrees, the notions of shock, destabilization, and decentering permeated the aesthetic choices and technical practices made by these artists.

As a tactic, destabilizing and defamiliarizing the audience in the service of politicizing aesthetics predates digital computing. At the conclusion of his 1935 essay on "The Work of Art in the Age of its Technological Reproducibility," philosopher Walter Benjamin observed the material reproducibility of art forms "revolutionizes" the social function of art itself, potentially moving it from a basis in religious ritual to one based on political struggle (Benjamin 2008: 25.) Benjamin argues that revolutionary artists must juxtapose tactics provoking both destabilization and reflection in order to awaken a progressive political consciousness in their audience. Art acknowledged as both a product of collective sociotechnical endeavor-as made by many people working together - and for a collective audience was for Benjamin the most effective means to transcend habituation, shocking viewers into a reconsideration of their political situation.

For Benjamin, cinema was the technologically mediated art form most amenable to the production of radical politics. "Art," he suggested, "will tackle the most difficult and most important tasks where it is able to mobilize the masses" (Benjamin 2008: 40). The jarring formal or technical aspects of a medium like cinema (or the mixed-media collages favored by the Dadaists) worked to reinforce their historically contingent role 
as psychologically and emotionally disruptive for the viewer, turning "the artwork into a missile" (Benjamin 2008: 39).

At the time of its introduction, the novelty of the cinematic form had a visceral impact: the "shock effects" of its form were matched by its widespread proliferation as a familiar component of everyday urban life. This defamiliarization within familiarity was what Benjamin suggested produced potent political reflection on the part of the audience. For Benjamin, the audience's heightened presence of mind was a potential source for individual political revelation and by extension political revolution. In the case of the data artists interviewed, the milieu in need of defamiliarization is not limited to the dark confines of the cinema but consists of the digitally mediated contours of everyday locations and experiences.

We argue that artists working with data tools today are finding new means to produce visceral effects in the service of defamiliarizing familiar forms of digitally mediated interaction. Benjamin recognized the ways in which a continuum of destabilization effects could exist across different media formats, as well as the link between embodied sensation and ethical judgment. Benjamin suggested defamiliarization stems from the visceral and embodied experience of the body. "Film has freed the physical shock effect," Benjamin writes, "which Dadaism had kept wrapped, as it were, inside the moral shock effect" (Benjamin 2008: 39). This physical process triggers a heightened sense of mental reflection; as such, viscerality is foundational to an ethics of aesthetics. From Oliver's Prism: The Beacon Frame to Dewey-Hagborg's Stranger Visions, the artists we interviewed were producing work in this same mold, seeking to engage audiences viscerally and emotionally precisely to "heighten their presence of mind."

One element differentiating the work of the various artists we interviewed was the extent to which its technical or formal aspects actively sought to disrupt embodied experience of an audience. Yet even for artists producing more straightforward - and perhaps less shocking - representations of human enmeshment within data analytic systems, the defamiliarizing process Benjamin describes was present: not necessarily through sudden formal changes within one medium but through documenting the habitual intrusions of digital data's consequences into the rhythm of life and presenting these intrusions in unexpected ways to the audience.

Indeed, artists often saw troubling or disrupting a habituated attitude to data platforms and devices as a key goal. "The feeling I was always trying to evoke is vertigo, this kind of network vertigo," suggested Oliver [interview]. "We like to allow ourselves to even terrify a little bit and see that as cathartic moments in a way that doesn't alienate people but lets them in." These vertiginous effects were described by many of the artists we interviewed. However, there was consensus that such effects could not occur in a vacuum: to engender audience reflection in the long-term, audience education and reflection were key. "I can send any number of people within an electromagnetically delimited space to a rogue base station transceiver and can just simply force associate them to a transceiver and then start pushing data on to their device," pointed out Oliver in reference to his controversial Prism: The Beacon Frame [interview]. Many artists also noted concrete plans for educating and contextualizing were vital to the ethics of their art practice. "You need to have a long period of unpacking," Oliver observed. "There needed to be a way to let people in."

\section{Ethics in Data Art Practice}

Benjamin's famous closing declaration to "The Work of Art in the Age of Its Technological Reproducibility" claims both "the logical outcome of fascism is an aestheticizing of political life" (Benjamin 2008: 41) and "communism replies by politicizing art" (42). As a response to the fascism of human "selfalienation," in which politics is aestheticized through a technological apparatus that, in Benjamin's terms, is "pressed into the production of ritual values," the digital artists in our study responded by tactically foregrounding the political and ethical implications of their work through the production of visceral and emotional effects. Artists intended these effects to prompt "heightened presence of mind." Whether these practices were always successful, artists clearly felt that the politicization of digital aesthetics was necessary to have an ethical impact, particularly in an era of rising populism around the world. 
While Benjamin's work helps explicate the political stakes of art, his analysis is less helpful in unpacking the ethical dilemmas of artists themselves. Many of the artists we interviewed noted a paradox: in challenging structures of technological, economic, and institutional power through art incorporating digital technologies, the artists themselves risked replicating those same structures of power. Author and artist Burrington noted the impulse toward technical mastery in the community, which for some artists seemed to become an end in itself. "There's a kind of culture emerging," Burrington noted, "especially with the surveillance stuff - I've often called it Spy vs. Spy — in which artists working with things related to national security and surveillance tend to be really into the adversarial role it places them in, against an institution of power. But they're doing a similar thing the institutions do" [interview]. Other sets of practitioners, such as Goldsmiths, University of London's Forensic Architecture group or the University of Toronto's Citizen Lab, also must engage with this challenging dynamic: mobilizing the technologies of institutional oppression entails at least a passing familiarity with such oppression's own goals and aims.

Artist Allison Burtch uses the term "cop art" to describe the same danger noted by Burrington [interview]. Burtch, a faculty member at New York City's School for Poetic Computation, referenced her 2013 video art piece, Watching You (Burtch 2013), in which participants could have CCTV images of themselves removed from the piece's database if they provided, anonymously, written accounts of intimate thoughts or feelings. "I wasn't going to make an art project where I just stalked someone," Burtch observed. "That's cop art. ... I'm not going to stalk someone non-consensually. The problem with surveillance is you don't really know what's happening, and we've designed it that way to be powerful" [interview]. The concept of "cop art" signals a central ethical challenge for many of the artists we interviewed: in the process of seeking to defamiliarize their audiences, how should artists engage responsibly with incorporating data practices of machine learning, predictive analytics, and data harvesting in ways taking into account the complexities of power dynamics, context, and audience?

Many artists were explicit in their wariness in reproducing unethical practices of surveillance as they attempted to critically interrogate the dynamics of digital technologies. However, many of the artists we interviewed also claimed that the mantle of "artist" meant working in a space of social and even legal exception. Oliver's aforementioned work, Prism: The Beacon Frame, exemplifies the tensions around what kind of project is determined to be art, and when. Organizers of Berlin's Transmediale festival shut down Prism under the threat of legal action, ironically because the art piece was contravening anti-surveillance laws. "Art needs to have a foot out of society in order to critically engage it . . challenging moral norms and even challenging ethics as constants becomes an ethical responsibility of its own," suggested Oliver [interview].

Some of the artists we spoke to suggested that the artistic intent of their work itself helped differentiate their critical stances from state and corporate surveillance and justified the use of others' personal data for creative projects. "What we are talking about is one artist broke and barely surviving," Cirio pointed out, "against a company that has unlimited budget, unlimited resources, and unlimited data ... what I do is nothing compared to what is actually going on" [interview]. These tensions animated many artists' sense of their own ethical process. "Sometimes I think it is the duty of artists, speaking with my big beret on, to just do the thing might be deeply problematic as well but to do it within that creative and critical framework," Bridle suggested [interview]. To have an ethical impact on society at large, these artists claimed the need to contest the nature and structure of societal ethics more broadly.

Many of the artists we spoke to had been forced to consider the legal bounds of their work in the course of working with data and computation tools. They described the legal restrictions around using personal data, surveillance, and hacking as often necessary but not particularly desirable or applicable to their artistic practice: "It's not as though there's sort of a governing body of the loose network of artists working with these topics who can say like, "This is okay," Burrington pointed out [interview]. Yet perhaps paradoxically, many of the artists we interviewed advocated for the ability to push legal boundaries, agreeing that conceptual and legal space was necessary for generative artistic experimentation. "I don't want a committee sitting around and deciding what kinds of works are ethically or morally acceptable," declared 
Poitras, "which isn't to say we shouldn't engage and ask questions about ethics and morals" (Poitras and Crawford 2015). Artists cited recent cases in which work involving emerging technologies had come into conflict with the authorities, such as the arrest of bio-artist Steven Kurtz on terrorism charges, later dismissed, in 2004 (Duke 2004).

For these artists, ethics practices developed socially in the context of shared conversations about aesthetics. Conversations about the ethics of particular data art practices took place in the context of social ties, preexisting friendships, or working relationships. Artists articulated a delicate balancing act: engaging with the social implications of a particular work while still respecting the creative autonomy of individual artists. Crucially, artists explained their responsibility to be courageous in discussing the ethics of a particular work through making aesthetic or formal critiques of a piece. The ability to navigate the ethical challenges of aesthetic practice was thus seen by many of our interlocutors as a criterion for individual artistic quality.

\section{Data Artists and the Ethics of Ambiguity}

The formal connection between ethics and aesthetics is supported by a position in the philosophy of aesthetics known as moderate moralism (Carroll 2000): when information itself is a palette, it highlights the interconnections between the materials of practice, the producers of those materials, the ethical implications of an artwork's effects. Artists pointed to a loose set of pragmatic norms around which interventions might be ethical and which might not be. Disagreement around the ethics of particular works often stemmed from artists' differing conceptions of the work's aesthetic impact in a particular context. The artists we interviewed outlined a number of possible strategies to articulate their own practice around making these assessments. "I try to separate "ethics' from 'morality," Cirio suggested. "My projects are not totally moral in a way because of the provocations push the limits of social norms... but I always try to be ethical, so for example, they [subjects] can ask to be removed from this database" [interview].

Many artists noted the ways in which ethical concerns were incorporated into the substance of aesthetic or formal critiques, particularly when the artist concerned with a work did not know its maker personally. "I see a responsibility to not hurt anyone as much as I can . . obviously not intentionally but also to take measures to try and not hurt anyone unintentionally," noted McCarthy [interview]. Artists observed public engagement around data ethics was also in its infancy, and artists could actively provide valuable insights to the broader conversation if they chose. Yet what types of interventions were valuable was still open for significant debate.

To complement Benjamin's observations on the political stakes of art, we suggest further recourse to a powerful parallel strain of thought from post-war existentialist philosopher Simone de Beauvoir: what she terms "the ethics of ambiguity." In Beauvoir's ([1949] 2011: 138) words, an ambiguous ethics suggests all people "must decide upon the opportuneness of an act and attempt to measure its effectiveness without knowing all the factors that are present." The effects of artistic provocations may be unknowable, but for Beauvoir, it is the ethical duty of the artist to both make the attempt and to be reflective of their own role and agency as ethical actors (Raley 2009).

Artists expressed awareness of the ways in which ambiguity was expressed through their engagement with the material world, the built environment, and the complex routines of how individuals use digital technology. They frequently sought to leverage this ambiguity to produce destabilizations, defamiliarizations, shock, and active reflection in their audiences. Some artists placed themselves at the embodied center of these defamiliarizations: a work like artist and researcher Mimi Onuoha's Pulse (Onuoha 2016), a site-specific 2016 performance in which Onuoha connected herself to a heart monitor and broadcast a visualization of her heartbeat in real time, is one example of how the specific temporal and spatial ethical position of the individual might complicate or subvert the classifying and quantifying metrics of digital data. "It's an uncertainty that focuses attention and brings up complicated questions," noted Bridle [interview]. "A choice," Beauvoir ([1949] 2011: 138) noted regarding the moral responsibility invested in aesthetic choice, "is no more arbitrary than a hypothesis; it excludes neither reflection nor even method; but 
it is also free, and it implies risks must be assumed as such." The openness theorized by Beauvoir is thus at the center of art's liberatory potential.

Ethics is often understood as a question of means and ends. Reading Benjamin and Beauvoir alongside the experience of the artists we spoke to suggests these two categories are increasingly conflated into one continuum of practice in the eyes of artists who engage with data systems. A work made unethically is deleterious to its aesthetic value precisely because, as Raley (2009: 115) suggests, it is merely "generative," and not also reflective. This synthesis is not a new philosophical idea: as Wittgenstein remarked, "ethics and aesthetics are one" inasmuch as both are aspects of "the enquiry into what is valuable, or, into what is really important ... the enquiry into the meaning of life, or into what makes life worth living, or into the right way of living" (Collinson 1985: 267). Yet the fusing of means and ends gains new currency in an epoch where digital systems are simultaneously tools for creativity and mechanisms for corporate and state surveillance.

For artists, there is a direct link between engaging in a personal "ethics of ambiguity" and an aesthetic practice of defamiliarization in the service of emancipatory politics. "A lot of the artists that work with that kind of data and a lot of the artists we work with in general are good artists, and so they already are thinking about those things," suggested curator and editor Heather Corcoran, "and in general what makes a good artist is somebody who's well-informed, thinking critically, engaged with the language around the topics they're using, and adding something new to the conversation." An ethics of ambiguity confronts artists with the responsibilities of autonomous choice and its consequences; defamiliarization is the formal outcome that best translates this ethical impulse to the audience, prompting reflection and heightened presence of mind. The conscious bundling of the aesthetic and the ethical in the minds of artists we interviewed was what kept this twinned impulse politically emancipatory, along with the expression of this connection in both social interactions and formal critiques.

\section{Conclusion: Data Ethics—and Politics—for Artists and Everyone Else}

Data tools, predictive analytics, and techniques like machine learning are all playing an increasingly central role in the art world. Through our interviews, we found artists are the vanguard of exploring the ethical, political, and aesthetic potential of emerging technologies and in recognizing the interconnection between the techniques of artistic production and their political effects. The experience of these artists suggests that the explicit ties between technical aesthetics and politics will increasingly become central not just for artists but also for everyone who works with data tools and the AI field more generally.

One barrier to a shared and nuanced understanding of the ethical issues raised by digital art practices is a lack of literacy regarding the technologies themselves. Bridle noted that the technical complexities of computational platforms were themselves a part of the reason art criticism had failed to fully engage with the ethical questions raised by art drawing on these tools. "Most people who are versed in art criticism just don't understand technology," Bridle pointed out. "You can't critique a painting if you don't understand how paint works really well. The quality, the mixing, or the brushwork, the materiality of it ... the same goes for how the artist works with technology" [interview]. Until art critics engage more deeply with the technical frameworks of data art, their ability to analyze and assess the merits of these works - and their attendant ethical dilemmas - may be limited.

This challenge also has lessons for digital technology critique more broadly: we need sustained attention on the granular details of digital production and practice, for instance through work in science and technology studies (STS) and the applied philosophy of technology (Friedman and Nissenbaum 1996; Crawford and Schultz 2013; Shilton 2018) in order to formulate alternative visions with both material and moral force. The increasingly broad literature on the fairness, accuracy, and ethics of algorithmic systems (Barocas and Selbst 2016; Crawford and Schultz 2013; Barocas et al. 2017) will also benefit from engagement with artists and other creative professionals working with digital systems. 
As computational tools become more widespread not only in the arts but also in other sectors of daily life, thinking through not just data ethics but also digital politics will be necessary and desirable for artists and for a wide variety of professions (Moor 2001). STS scholars concerned with the incorporation of particular social or ethical values into digital design (Friedman, Kahn, and Borning 2006; Nissenbaum 2011; Shilton 2013) have expressed similar concerns to those we heard in our interviews: that inattention to ethics embedded in the design and use of digital technologies will worsen already extant social problems (Barocas and Selbst 2016). "There's no real computer science ethics," Dewey-Hagborg pointed out, "and there really should be" [interview]. The experience of artists reinforces a point we have each separately argued elsewhere: that abstract ethics conversations are a necessary but not sufficient condition for progressive politics around digital technologies and that everyday digital practice is the terrain around which broader ethical and political ends must be staked out.

Data ethics is itself a contested field of ethical enquiry (Johnson 2007; Markham, Tiidenberg, and Herman 2018; Barocas and boyd 2017), but a close relationship to computer science seemed to offer some artists a clearer lens through which to consider the ethics of their work (Maffesoli 1991). "Ethics have never been an easy part of the art work," Burrington pointed out, "but in some ways they might be more readily translated into this particular branch of the art world because there already is sort of a relationship to data ethics, and we have some kind of idea of what that looks like." Ultimately, as artist and academic Golan Levin suggested, artists tended to agree that ethical conversations were developing as a community and that creating boundaries around acceptable practices ought to be a community practice [interview].

The artists we interviewed had a deep awareness of how the ethics of data practices were linked with broader political debates around social media platforms and AI. For Poitras, the goal of her work is "to bridge the divide between our intellectual understanding and an emotional understanding of things like torture, occupation, and surveillance" (Poitras and Crawford 2015). The Snowden leaks reinforced concerns within the artistic community around privacy and dataveillance (Barnard-Wills and Barnard-Wills 2012) and galvanized previously less politicized artists (Graves 2014). "Artists for as long as they've been working with technology have been thinking about privacy," observed Corcoran, former editor of the digital arts journal Rhizome [interview]. "Being able to not just talk about this stuff as a kooky theory but being able to point to it as being true has changed the conversation." Artists suggested Master of Fine Arts (MFA) and interdisciplinary art and technology programs would benefit from explicit discussions around the ethics of computational practice - much like computer scientists and electrical engineers, whose own lack of ethical training is also a matter of increasing concern.

As computational tools become standard across creative practices, artists working to illuminate the privacy and surveillance with large-scale data have an important role to play in the wider data ethics discussion. "When we start automating systems and abdicating personal judgments-you know what kinds of biases emerge in those systems," Dewey-Hagborg observed [interview]. "I noticed that my own mistakes and faults and biases got implanted in the systems I was making. And so that made me concerned about the potential for real injustice happening when these systems were automated." We argue conversations in the art world around the pragmatic ethics of data art practice are in fact a positive model for other computational fields to follow: artists saw value in reaching shared normative practices through engagement between artists and audiences, suggesting a model for participation and collaboration often missing in other forms of digital research and development.

We suggest society at large will be increasingly called on to make the kinds of judgments - aesthetic, ethical, and political - that the artists we interviewed were simultaneously exploring, critiquing, and struggling with. The ethical practices of artists working with computational tools are relevant to the wider debates about data ethics, not just because they invoked technical systems but because they were seeking to make explicit those parts of technology in everyday life that tend to slip below the surface (Boehner et al. 2007). Rather than being sidelined in the debates about ethics in artificial intelligence and data practices more broadly, artists should be centered as practitioners who are already seeking to make public the political and cultural tensions in using data platforms to reflect on our social world. 


\section{References}

Ahnert, Laurel. 2017. The Surveillance Commodity, Unequal Exchange, and the (in)Visible Subject in Hasan Elahi's Tracking Transience. Social Text 35 (3): 1-16.

Banks, Mark. 2017. Creative Justice: Cultural Industries, Work and Inequality. London: Rowan \& Littlefield.

Barnard-Wills, Katherine, and David Barnard-Wills. 2012. Invisible Surveillance in Visual Art. Surveillance \& Society 10 (3/4): 204-14.

Barocas, Solon, and Andrew D. Selbst. 2016. Big Data's Disparate Impact. California Law Review 104: 671-732.

Barocas, Solon, and danah boyd. 2017. Engaging the Ethics of Data Science in Practice. Communications of the ACM 60 (11): 2325.

Barocas, Solon, danah boyd, Sorelle Friedler, and Hanna Wallach. 2017. Social and Technical Trade-Offs in Data Science. Big Data 5 (2): 71-72.

Beauvoir, Simone de. (1949) 2011. The Works of Simone de Beauvoir: The Second Sex and The Ethics of Ambiguity. CreateSpace Independent Publishing Platform.

Benjamin, Walter. 2008. The Work of Art in the Age of Its Technological Reproducibility: Second Version. In The Work of Art in the Age of Its Technological Reproducibility and Other Writings on Media, edited by Michael W. Jennings, Brigid Doherty, and Thomas Y. Levin, 19-55. Cambridge, MA: Belknap Press.

Boehner, Kirsten, Rogério DePaula, Paul Dourish, and Phoebe Sengers. 2007. How Emotion Is Made and Measured. International Journal of Human-Computer Studies 65: 275-91.

Bolter, Jay David, and Richard Grusin. 2000. Remediation: Understanding New Media. Cambridge, MA: MIT Press.

boyd, danah, and Kate Crawford. 2012. Critical Questions for Big Data. Information, Communication \& Society 15 (5): $662-79$.

Bridle, James. 2014a. The Right to Flight. Installation. Bold Tendencies, Peckham, London. http://right-to-flight.com/ [accessed September 3, 2014].

Bridle, James. 2014b. The Right to Flight: Why I'm Flying a Balloon Over London This Summer. Guardian, July $15,2014$. https://www.theguardian.com/cities/2014/jul/15/the-right-to-flight-why-im-flying-a-balloon-over-london-this-summer.

Bridle, James. 2017. Autonomous Trap 001. Installation. Mount Parnassus. https://jamesbridle.com/works/autonomous-trap-001 [accessed December 5, 2017].

Burtch, Allison. 2013. Watching You. Video installation. NYU ITP, New York City. http://www.allisonburtch.net/watching-you/ [accessed December 11, 2018].

Carroll, Noel. 2000. Art and Ethical Criticism: An Overview of Recent Directions of Research. Ethics 110 (2): 350-87.

Cirio, Paolo. 2013. Street Ghosts. Outdoor installation. Various locations. http://streetghosts.net [accessed December 5, 2017].

Collinson, Diané. 1985. 'Ethics and Aesthetics Are One'. British Journal of Aesthetics 25 (3): 266-72.

Crawford, Kate. 2018. AI Now: Social and Political Questions for Artificial Intelligence. Video, 1:15:30. University of Washington. https://www.youtube.com/watch?v=a2IT7gWBfaE [accessed September 2, 2018].

Crawford, Kate, and Jason Schultz. 2013. Big Data and Due Process: Toward a Framework to Redress Predictive Privacy Harms. Public Law and Legal Theory Research Paper Series, Working Paper No. 13-64. New York: New York University School of Law.

Dewey-Hagborg, Heather. 2013. Stranger Visions. Sculpture and multimedia installation. Various locations. http://deweyhagborg.com/projects/stranger-visions [accessed December 13, 2018].

Dewey-Hagborg, Heather. 2017. Probably Chelsea. Sculpture and multimedia installation. Fridman Gallery, New York City. https://deweyhagborg.com/projects/probably-chelsea [accessed December 13, 2018].

Dignum, Virginia. 2018. Ethics in Artificial Intelligence: Introduction to the Special Issue. Ethics and Information Technology 20 (1): $1-3$.

DuBois, Luke. 2011. A More Perfect Union. Works on paper. Various locations. http://lukedubois.com/ [accessed December 13, 2018].

Duke, Lynne. 2004. The FBI's Art Attack. Washington Post, February 6, 2004. http://www.washingtonpost.com/wpdyn/articles/A8278-2004Jun1.html.

Feldman, Allen. 2005. On the Actuarial Gaze. Cultural Studies 19 (2): 203-26.

Finn, Jonathan. 2012. Surveillance Studies and Visual Art: An Examination of Jill Magid's Evidence Locker. Surveillance \& Society 10 (2): 134-49.

Francastel, Pierre. 2000. Art and Technology in the Nineteenth and Twentieth Centuries. New York: Zone.

Friedman, Batya, and Helen Nissenbaum. 1996. Bias in Computer Systems. ACM Transactions on Information Systems 14 (3): $330-47$.

Friedman, Batya, Peter H. Kahn, and Alan Borning. 2006. Value Sensitive Design and Information Systems. In Human-Computer Interaction in Management Information Systems: Foundations, edited by B. Schneiderman, Ping Zhang, and D. Galletta, 34872. New York: M.E. Sharpe.

Gonzalez, Jennifer. 2009. The Face and the Public: Race, Secrecy, and Digital Art Practice. Camera Obscura: Feminism, Culture, and Media Studies 24 (1): 37-65.

Grau, Oliver. 2004. Virtual Art: From Illusion to Immersion. Cambridge, MA: MIT Press.

Graves, Jen. 2014. What Only Artists Can Teach Us About Technology, Data, and Surveillance. The Stranger, December 10, 2014. http://www.thestranger.com/seattle/what-only-artists-can-teach-us-about-technology-data-andsurveillance/Content?oid=21162466.

Gunn, Daniel P. 1984. Making Art Strange: A Commentary on Defamiliarization. Georgia Review 38 (1): $25-33$.

Higgins, Hannah, and Douglas Kahn, eds. 2012. Mainframe Experimentalism. Chicago, IL: University of Chicago Press.

Isaac, Mike. 2015. Behind Silicon Valley's Self-Critical Tone on Diversity, a Lack of Progress. New York Times, June $28,2015$. 
http://bits.blogs.nytimes.com/2015/06/28/new-diversity-reports-show-the-same-old-results/.

Johnson, Deborah G. 2007. Ethics and Technology 'In the Making': An Essay on the Challenge of Nanoethics. Nanoethics 1 (1): 21-30.

Kammerer, Dietmar. 2004. Video Surveillance in Hollywood Movies. Surveillance \& Society 2 (2/3): 464-73.

Latour, Bruno. 1983. Give Me a Laboratory and I Will Raise the World. In Science Observed: Perspectives on the Social Study of Science, edited by Karin D. Knorr-Cetina and Michael Mulkay, 141-69. London: Sage.

Levin, Sam. 2017. Black and Latino Representation in Silicon Valley Has Declined, Study Shows. Guardian, October 3, 2017. https://www.theguardian.com/technology/2017/oct/03/silicon-valley-diversity-black-latino-women-decline-study.

Levin, Thomas Y., Ursula Frohne, and Peter Weibel, eds. 2002. CTRL [SPACE]: Rhetorics of Surveillance from Bentham to Big Brother. Karlsruhe, DE: ZKM Center for Art and Media/MIT Press.

Lyon, David. 2014. Surveillance, Snowden, and Big Data: Capacities, Consequences, Critique. Big Data \& Society 1 (2): 1-13.

Madden, Mary, and Lee Rainie. 2015. Americans' Attitudes About Privacy, Security and Surveillance. Internet and Technology (Report). New York: Pew Research Center. http://www.pewinternet.org/2015/05/20/americans-attitudes-about-privacysecurity-and-surveillance/ [accessed May 3, 2015].

Maffesoli, Michel. 1991. The Ethics of Aesthetics. Theory, Culture \& Society 8: 7-20.

Markham, Annette N., Katrin Tiidenberg, and Andrew Herman. 2018. Ethics as Methods: Doing Ethics in the Era of Big Data Research-Introduction. Social Media + Society 4 (3). https://journals.sagepub.com/doi/full/10.1177/2056305118784502.

Marks, Laura U. 2010. Enfoldment and Infinity: An Islamic Genealogy of New Media Art. Cambridge, MA: MIT Press.

Marx, Gary T. 2009. Soul Train: The New Surveillance in Popular Music. In Lessons from the Identity Trail Anonymity, Privacy and Identity in a Networked Society, edited by Ian Kerr, Valerie Steeves, and Carole Lucock, 377-98. Oxford: Oxford University Press.

McCarthy, Lauren. 2013. Crowdpilot. iOS application. http://www.crowdpilot.me/ [accessed December 17, 2018].

Metcalf, Jacob, Emily F. Heller, and danah boyd. 2016. Perspectives on Big Data, Ethics, and Society. New York: Council for Big Data, Ethics, and Society.

Moor, James H. 2001. The Future of Computer Ethics: You Ain't Seen Nothin' Yet! Ethics and Information Technology 3 (September): 89-91.

Mufson, Beckett. 2017. Meet the Artist Using Ritual Magic to Trap Self-Driving Cars. Vice, March $18,2017$. https://creators.vice.com/en_us/article/meet-the-artist-using-ritual-magic-to-trap-self-driving-cars.

Muir, Lorna. 2015. Transparent Fictions: Big Data, Information and the Changing Mise-en-Scène of (Government and) Surveillance. Surveillance \& Society 13 (3/4): 354-69.

New York Times Editorial Board. 2014. Silicon Valley's Diversity Problem. New York Times, October $4,2014$. http://nyti.ms/1xaAPdt.

Nissenbaum, Helen. 2011. From Preemption to Circumvention. Berkeley Technology Law Journal 26 (3): 1,367-86.

Oliver, Julian. 2014. Prism: The Beacon Frame. Multimedia installation. Transmediale Festival, Berlin. http://julianoliver.com/output/the-beacon-frame [accessed December 17, 2018].

Onuoha, Mimi. 2016. Pulse. Performance (one-time). Site-specific. http://mimionuoha.com/pulse/ [accessed December 16, 2018].

Pasquale, Frank. 2015. The Black Box Society. Cambridge, MA: Harvard University Press.

Paul, Christine. 2015. Digital Art. London: Thames \& Hudson.

Perini, Julie. 2010. Art as Intervention: A Guide to Today's Radical Art Practices. In Uses of a Whirlwind, edited by Team Colors Collective, 183-97. Chico, CA: A.K. Press.

Poitras, Laura, and Kate Crawford. 2015. Divorce Your Metadata: A Conversation Between Laura Poitras and Kate Crawford. Rhizome, June 9, 2015. http://rhizome.org/editorial/2015/jun/9/divorce-your-metadata/.

Pollack, Barbara. 2014. When Does Surveillance Art Cross the Line? ARTnews, September 9, 2014. http://www.artnews.com/2014/09/09/privacy-and-surveillance-art/.

Popper, Frank. 2006. From Technological to Virtual Art. Cambridge, MA: MIT Press.

Raley, Rita. 2009. Tactical Media. Minneapolis: University of Minnesota Press.

Remes, Outi, and Pam Skelton, eds. 2010. Conspiracy Dwellings: Surveillance in Contemporary Art. Newcastle, UK: Cambridge Scholars.

Rieland, Randy. 2014. 7 Ways Technology Is Changing How Art Is Made. Smithsonian.com, August $27,2014$. http://www.smithsonianmag.com/arts-culture/7-ways-technology-is-changing-how-art-is-made-180952472/?no-ist.

Rosen, David, and Aaron Santesso. 2013. The Watchman in Pieces: Surveillance, Literature, and Liberal Personhood. New Haven, CT: Yale University Press.

Roth, Evan. 2012. Multi-Touch. Works on paper. Various locations. http://www.evan-roth.com/work/multi-touch-finger-paintings/ [accessed December 17, 2018].

Shanken, Edward A. 2002. Art in the Information Age: Technology and Conceptual Art. Leonardo 35 (4): $433-38$.

Shilton, Katie. 2013. Values Levers: Building Ethics into Design. Science, Technology, \& Human Values 38 (3): $374-97$.

Shilton, Katie. 2018. Engaging Values Despite Neutrality. Science, Technology, \& Human Values 43 (2): $247-69$.

Shklovskij, Viktor. 1998. Art as Technique. In Literary Theory an Anthology, edited by Julie Rivkin and Michael Ryan, 8-14. Malden, MA: Wiley Blackwell.

Stark, Luke. 2016. The Emotional Context of Information Privacy. Information Society 32 (1): 14-27.

Steiner, Henriette, and Kristin Veel. 2011. Living Behind Glass Facades: Surveillance Culture and New Architecture. Surveillance $\&$ Society $9(1 / 2): 215-32$.

Stinson, Liz. 2014. These Aren't Abstract Paintings, They're iPhone Smudges. Wired, July $30,2014$. https://www.wired.com/2014/07/these-arent-abstract-paintings-theyre-huge-images-of-iphone-smudges/

Tufekci, Zeynep. 2017. Twitter and Tear Gas: The Power and Fragility of Networked Protest. New Haven, CT: Yale University 
Press.

Vallor, Shannon. 2018. An Introduction to Data Ethics. (Course module.) Santa Clara, CA: Markkula Center for Applied Ethics. Wang, Yilun, and Michal Kosinski. 2018. Deep Neural Networks Are More Accurate Than Humans at Detecting Sexual Orientation from Facial Images. Journal of Personality and Social Psychology 114 (2): 246-57.

Westin, Alan F. 2003. Social and Political Dimensions of Privacy. Journal of Social Issues 59 (2): 431-53.

Whitson, Jennifer R., and Bart Simon. 2014. Game Studies Meets Surveillance Studies at the Edge of Digital Culture: An Introduction to a Special Issue on Surveillance, Games and Play. Surveillance \& Society 12 (3): 309-19.

Zimmer, Catherine. 2015. Surveillance Cinema. New York: New York University Press. 